$\begin{array}{ll}\text { Research Square } & \begin{array}{l}\text { Preprints are preliminary reports that have not undergone peer review. } \\ \text { They should not be considered conclusive, used to inform clinical practice, } \\ \text { or referenced by the media as validated information. }\end{array}\end{array}$

\title{
Analysis of pigment cell composition, pigment content, tyrosinase content and activity of three kinds of loaches, Misgurnus anguillicaudatus from Poyang Lake
}

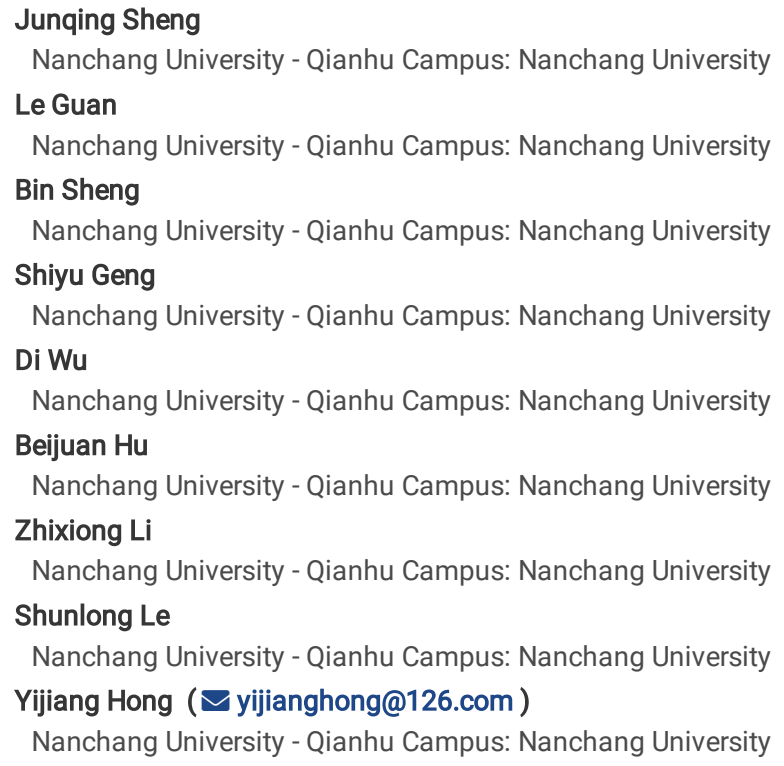

\section{Research Article}

Keywords: Misgurnus anguillicaudatus, pigment cell, pigment content, tyrosinase content, tyrosinase activity

Posted Date: February 16th, 2021

DOI: https://doi.org/10.21203/rs.3.rs-174546/v1

License: (c) (7) This work is licensed under a Creative Commons Attribution 4.0 International License. Read Full License

Version of Record: A version of this preprint was published at Journal of Fish Biology on November 9th, 2021. See the published version at https://doi.org/10.1111/jfb.14945. 


\section{Abstract}

Loaches, Misgurnus anguillicaudatus, from Poyang Lake are a small economic fish, falling into three categories with typical blackspot characteristics, namely, big blackspot loaches (BBL), small blackspot loaches (SBL), and non-blackspot loaches (NBL), respectively. Pigment cell composition, pigment content, tyrosinase content and activity of three kinds of loaches were investigated. Our results showed that there were three types of skin pigment cells, namely, melanophores, xanthophores and iridophores. Melanophores in dorsum were more than in abdomen. Melanophore cytosomes in BBL were larger than those in SBL and NBL, and melanosomes were the largest in stage four. The melanophores in dorsal skin of SBL or NBL were small cell bodies, spindle-like, and in chain distribution. There was an extremely significant difference in melanin content in BBL between the dorsum and abdomen $(P<0.01)$. There were no significant differences in melanin abdominal content, lutein and carotenoid contents among three kinds of loaches $(P>0.05)$. In dorsal skin, tyrosinase content was the highest in $B B L$, and it was significantly lower in NBL than in $B B L$ and $S B L(P<0.01)$. This study reveals differences in pigment and tyrosinase content in three kinds of loaches and provides a theoretical basis for further study of the mechanism of black spot formation.

\section{Introduction}

Pigment patterns depend on chromatophore interactions(Darias et al., 2013; Eom, Bain, Patterson, Grout, \& Parichy, 2015; Frohnhofer, Krauss, Maischein, \& Nusslein-Volhard, 2013; Maderspacher \& Nusslein-Volhard, 2003; Patterson \& Parichy, 2013; Singh, Schach, \& Nusslein-Volhard, 2014; Takahashi \& Kondo, 2008). Pigment cell is a type of cell containing pigment particles and reflective substance, and it is widely distributed in the skin of vertebrates such as fish, amphibians, and reptiles(Hurbain et al., 2008; Nishimura et al., 2010; Nishimura, Yoshida, Kunisada, \& Nishikawa, 1999). The pigment cells of fish consist of six different types of chromatophores with different chemical properties, including melanophores, erythrophores, xanthophores, leucophores, iridophores, and cyanophores(Cal, Suarez-Bregua, Cerdá-Reverter, Braasch, \& Rotllant, 2017; Fujii, 2000; Greenwood, Cech, \& Peichel, 2012; Guo, Huang, Qi, \& Zhang, 2007; Parichy, 2003). Eumelanin is mainly produced in fish, and pheomelanin is mainly produced in mammals, birds and reptiles(Bagnara, 1998; Fujii, 1993; Kottler, Kunstner, \& Schartl, 2015), whereas xanthophores and erythrophores generate pteridine and carotenoid pigments(Schartl et al., 2016). Iridophores and leucophores contain the stacked crystalline platelets (composed of purines, mainly of guanine) that are responsible for reflecting light (Fujii, 1993), while cyanophores contain blue pigment organelles with an unknown chemical composition(Goda \& Fujii, 1995; Schartl et al., 2016). Six types of cells above together could form a variety of body colors and pigment patterns in fish (Kelsh, 2004).

The body surface pigments of freshwater fish mainly include melanin, carotenoid, and purines, therefore the body colors of freshwater fish are mainly black and yellow. Melanin is synthesized by tyrosine under the action of tyrosinase, and bright body colors such as yellow and red are mainly determined by the quantity and distribution of carotenoid and lutein in skin and scale pigment cells.

According to the blackspot size in the skin, loaches, Misgurnus anguillicaudatus, from Poyang lake can be divided into big blackspot loaches (BBL), small blackspot loaches (SBL), and non-blackspot loaches (NBL). It was reported that the reproductive performance of BBL was significantly higher than that of SBL and NBL(Zhang, 2006). In the present study, the distribution of pigment cells and the melanosomes in melanophores in three kinds of $M$. anguillicaudatus were investigated, which would provide basic information for breeding of improved M. anguillicaudatus from Poyang Lake.

\section{Materials And Methods}

\subsection{Experimental materials}

BBL, SBL, and NBL (Fig. 1) were derived from Minhui Aquaculture Professional Cooperative of Dongxiang District, Fuzhou City, Jiangxi Province. The average body weight was $14.0 \pm 0.3 \mathrm{~g}$, and the average body length was $15.6 \pm 0.3 \mathrm{~cm}$. Before the experiment, the loaches were anesthetized with MS-222 (280 mg/L).

\subsection{Experimental methods}

\subsubsection{Preparation of temporary slices}

The surface skin of loaches was washed, and the same side skin in three kinds of adult loaches (dorsum and abdomen) was taken and laid on the slides without wrinkles. Temporary slices were prepared and observed with Nikon SMZ1270 microscope.

\subsubsection{Conventional paraffin section and hematoxylin-eosin staining}

Five skin samples from each type of loaches (BBL, SBL, and NBL) were taken from fish dorsum and abdomen, and fixed in $4 \%$ paraformaldehyde solution, dehydrated in ethanol, cleared in xylene, and embedded in paraffin. The 5-6 $\mu \mathrm{m}$ sections were stained with hematoxylin-eosin. Finally, the sections were taken photos with Nikon eclipse Ni-E microscope.

\subsubsection{Masson-Fontana staining}

The paraffin sections above were stained with Masson-Fontana to display the melanophores and were taken photos with Nikon eclipse Ni-E microscope.

\subsubsection{Iridophore staining}

The paraffin sections above were pretreated with $1.5 \%$ agarose and stained with $3 \%$ eosin and dye. Iridophore staining was conducted in the method reported by Ou et al(Ou, 2018).

\subsubsection{Transmission electron microscopy}

Small skin sections (dorsum and abdomen) were fixed in $2.5 \%$ glutaraldehyde which was buffered with $0.1 \mathrm{M}$ sodium cacodylate to $\mathrm{pH} 7.4$, then post-fixed in $1 \%$ OsO4 buffered with the same cacodylate, dehydrated and embedded in Epon 812. Ultrathin sections were stained with uranyl acetate and lead citrate, then observed with transmission electron microscopy HI7700 and taken photos with the Hitachi TEM system. 
2.2.6 Determination of melanin, carotenoids lutein, tyrosine content and activity in three kinds of loaches

The contents of melanin, carotenoids, and lutein in dorsal and abdominal skin of three kinds of loaches from Poyang Lake were determined with an enzymelinked immunosorbent assay kit (Shanghai Jining Biology and Technology Company). For each group, the experiment was conducted in five replicates. The tyrosine content and activity in dorsal skin, abdominal skin, and blood were determined with fish tyrosinase enzyme-linked immunosorbent assay kit (Shanghai Jining Biology and Technology Company). There were 5 replicates for each group.

\section{Experimental Results}

\subsection{Observation of skin temporary slices of three kinds of loaches}

The observation results of skin temporary slices of three kinds of loaches indicated that melanophores and xanthophores were present in the dorsal epidermis (Fig. 2). There were two types of melanophores in the dorsal epidermis of BBL. The first type was dendritic, and the cytoplasmic processes of the second type were less than that of the first type, but the cell body of the second type was bigger (Fig. 2-a). The melanophores of SBL were in an aggregation state (Fig. 2-

b). The melanocytes in NBL were in the same shape as the first type of melanocytes in BBL (Fig. 2-C). The xanthophores in three kinds of loaches are punctate.

No melanophores were observed in the temporary slices of the abdominal epidermis in all three kinds of loaches. Xanthophores were granular, and they were distributed in the abdominal epidermis of three kinds of loaches (Fig. 3a-c).

\subsection{Skin sections of three kinds of loaches}

\subsubsection{Skin microstructure of three kinds of loaches}

The paraffin sections of three kinds of loaches were H.E. stained. The microstructure of the skin in loaches was the same as that in most bony fishes, including epidermis and dermis (Fig. 4). The epidermis consisted of multiple flat epithelial cells, basal cells, pigment cells, and mucus cells. The imbricated scales were located in between the epidermis and the dermis. The dermis was composed of adventitia, stratum laxum, and stratum compactum. Measured with the ruler in the concerning software, the dorsal skin was found to be thicker than the abdominal skin in all three kinds of loaches (Fig. 4).

\subsubsection{Microstructure comparison between dorsal skin and abdominal skin of three kinds of loaches}

The comparison of dorsal skin microstructure indicated that the scale insertion of SBL was deeper than that of BBL and NBL. The cytosomes of melanophores were larger in BBL than in SBL and NBL. In dorsal skin of loaches, the melanophores were found in the epidermis and dermis, and they were mainly distributed in basal cells, stratum laxum, stratum compactum, and subcutaneous layer. No xanthophores were observed by H.E. staining methods (Fig. 5). Merely a few melanophores were found to be distributed in abdominal subcutaneous layer of loaches but these melanophores were not found in the abdominal epidermis and dermis of three kinds of loaches (Fig. 5).

\subsubsection{Melanophore staining with Masson-Fontana staining method}

Masson-Fontana staining was performed in the skin of three kinds of loaches, and the results further showed that the number of melanophores in the dorsum was significantly larger than that in the abdomen (Fig. 6). In the dorsal skin, the melanophores were found to be distributed in the epidermis and dermis of loaches. However, in the abdominal skin, no melanophores were observed in the epidermis, and there were only a small number of melanophores observed in the connective tissue in three kinds of loaches.

The cytosomes of melanophores in dorsal skin of BBL were the biggest, followed by those of SBL, and those of NBL was the smallest. The melanophores of BBL in dorsum were distributed separately, but those of SBL and NBL formed pigment bands. The melanophores in abdomen were squeezed and their shape couldn't be distinguished (Fig. 7).

\subsubsection{Iridophores staining}

The iridophores were observed in the dorsal and abdominal dermis of three kinds of loaches. The iridescent cell was long spindle-shaped, but there was little difference in the number and density among the three kinds of loaches (Fig. 8).

\subsubsection{Ultrastructure observation}

The number of melanosomes in the melanophores in dorsal skin was larger than that in abdominal skin (Fig. 9). For BBL, the number of melanosomes in dorsal and abdominal skins was the most in the fourth development stage, whereas for SBL, the number of melanosomes were larger in stage three and stage four than in stage one and stage two. For NBL, the melanosomes were found in stage one to stage three (Fig. 9d-f, j-k).

\subsection{Determination of melanin, lutein, total carotenoid and tyrosinase in three kinds of loaches}

\subsubsection{Contents of melanin, lutein and total carotenoid in the skin of three kinds of loaches}

The melanin content in the same part of three kinds of loaches was compared. The melanin content in the dorsum of BBL was found to be the highest (10.87 $\pm 0.69 \mathrm{ng} / \mathrm{ml})$ among three kinds of loaches, which was significantly higher than that of SBL $(P<0.01)$. The melanin content of NBL was $9.62 \pm 0.35 \mathrm{ng} / \mathrm{ml}$, which was lower than that of BBL, but there was no statistical significance $(P>0.05)$ (Fig. 10). In abdominal skin, there was no significant difference in melanin content among the three kinds of loaches.

The melanin content in the dorsal skin and abdominal skin of the same kind of loaches was compared, and the results showed that the melanin content in the dorsum was higher than that in the abdomen. Furthermore, for BBL, there was an extremely significant difference in melanin content between the dorsum and abdomen $(P<0.01)$. 
The content of lutein in the skin of three kinds of loaches was determined. The content of lutein in the dorsum of BBL was found to be the highest (1315.75 $\mathrm{ng} / \mathrm{ml})$. The content of lutein in the abdominal skin of NBL was the highest $(1226.38 \mathrm{ng} / \mathrm{ml})$. However, there was no significant difference in lutein content in the same part among different kinds of loaches, and there was no significant difference in lutein content of the same kind of loaches between different parts, either $(P>0.05)$ (Fig. 11).

The contents of total carotenoids in the dorsal skin of BBL, SBL, and NBL were $6.04 \pm 0.13 \mu \mathrm{g} / \mathrm{ml}, 6.08 \pm 0.18 \mu \mathrm{g} / \mathrm{ml}$, and $5.95 \pm 0.12 \mu \mathrm{g} / \mathrm{ml}, \mathrm{respectively}$, and there was no significant difference among them $(P>0.05)$. In the abdominal skin, the total carotenoid content of SBL was the lowest $(6.15 \pm 0.57 \mu \mathrm{g} / \mathrm{ml})$, but there was no significant difference among the three kinds of loaches.

The content of total carotenoids in the dorsal skin and abdominal skin of the same kind of loaches was compared. The results showed that the total carotenoid content was higher in the abdomen than in the dorsum, but there was no significant difference in the total carotenoid content in the skin among three kinds of loaches $(P>0.05)$ (Fig. 12).

\subsubsection{Tyrosinase content determination in dorsal skin and abdominal skin of three kinds of loaches}

The tyrosinase content in the skin of three kinds of loaches was determined. In the dorsal skin, the tyrosinase content in BBL was found to be the highest, reaching up to $1445.93 \mathrm{pg} / \mathrm{ml}$; the tyrosinase content in NBL was the lowest $(1237.55 \mathrm{pg} / \mathrm{ml})$, which was significantly lower than that in the other two kinds of loaches $(P<0.01)$. In the abdominal skin, the tyrosinase contents of BBL, SBL, and NBL were $1377.35 \mathrm{pg} / \mathrm{ml}, 1345.69 \mathrm{pg} / \mathrm{ml}$, and $1312.76 \mathrm{pg} / \mathrm{ml}$, respectively, but there was no significant difference among three kinds of loaches $(P>0.05)$. The tyrosinase content in dorsum of three kinds of loaches was higher than that in the abdominal skin, but there was no significant difference $(P>0.05)$ (Fig. 13).

\subsubsection{Determination of tyrosinase activity in skin and blood of three kinds of loaches}

The tyrosinase activities of serum and skin in three kinds of loaches were investigated. The results indicated that in the serum, the highest activity of tyrosinase was observed in NBL $(3.23 \mathrm{U} / \mathrm{ml})$, and the lowest was observed in BBL $(0.62 \mathrm{U} / \mathrm{ml})$, but there was no significant difference among three groups $(P>$ 0.05). In the dorsal skin, the tyrosinase activity in BBL was the highest, reaching $90.27 \mathrm{U} / \mathrm{ml}$, while it was the lowest in NBL (3.24 $\mathrm{U} / \mathrm{ml})$, and there was a significant difference between BBL and two other kinds of loaches $(P<0.01)$. However, in the abdominal skin, there was no significant difference in tyrosinase activity among three kinds of loaches $(P>0.05)$ (Fig. 14).

Comparison of the different parts of the same kind of loaches revealed that for BBL, tyrosinase activity in dorsal skin was significantly higher (90.27 $\mathrm{U} / \mathrm{ml}$ ) than that in serum and abdominal skin $(P<0.01)$. But there was no difference in tyrosinase activity among the three parts of the other two loaches $(P>0.05)$ (Fig. 14).

\section{Discussion}

The body color pattern of fish is rich and diverse, which might be due to the fact that fish contains different types of pigment cells, which can selectively absorb the light of a specific wavelength or reflect it through the pigment body(Van der Salm, Martinez, Flik, \& Bonga, 2004; Yanar \& Nazmi, 1999; Y. P. Zhang et al., 2015). This study found that the loaches contained melanophores, xanthophores and iridophores. The number of melanophores in the dorsal skin of loaches was larger than that in the abdominal skin, which led to the dark (cyan gray) back color and light (yellow) belly color. Our results were consistent with the previous report that the melanophores in dorsal skin of seven kinds of fishes were more than those in the abdominal skin, which might be attributed to the fact that fish could form a certain degree of camouflage color to avoid the attack of enemies(Yao, 2020). M. anguillicaudatus is a kind of benthic fish, who lives in the sediment or the bottom mud of water. To avoid the attack of enemies, their body colors are like the sediment or mud.

Our results indicated that the melanophores in the skin of loaches were distributed in the epidermis and dermis. Our results were in line with the previous study findings of paddlefish(Zarnescu, 2007) and Tibetan Plateau loaches(Ou, 2018). The visual color of xanthophores and erythrophores was reported to be mainly determined by the relative content and type of intracellular pigment particles (Bagnara., 1973). In this study, xanthophores were observed in the epidermis through temporary slices, however, they were not observed in the skin of all the three kinds of loaches with H.E. staining method, which was consistent with the previous research results of Pristella Maxillaris (Bian et al., 2019). The possible reasons might lie in that the xanthophores contained fat-soluble carotenoids and water-soluble dipyridine, and that pigment was easy to dissolve in the process of dehydration and repeated washing (Hirata, 2005). In this study, iridophores containing many color reflection substances with similar morphology were observed in the dermis of three kinds of loaches. Hirata et al. (Hirata, 2005) observed two types of iridophores with different sizes in zebrafish, while we observed one type of iridophores with the same size in three kinds of loaches. Based on this finding, it could be speculated that there might be a difference in their blackspot, but no difference in the body color among three kinds of loaches.

Our data indicated that the aggregation degree of melanophores in the dorsal epidermis was different among three kinds of loaches. Mature melanophores exhibited dendritic structure and larger cell body, but immature melanophores displayed no dendritic structure and smaller cell body (Nishimura et al., 1999). When mature melanophores entered the quiescent phase, dendrites decreased and cell bodies became smaller(Nishimura et al., 2010). Our results indicated that the melanophores in BBL were mostly dendritic, and the cell body was the biggest among three kinds of loaches and that most of the melanophores in SBL and NBL were of the same size. Black spots appearing in the "big flowers" of Oujiang color carp might be due to the uneven distribution of melanophores (Yu, 2020). In this study, the number, morphological structure, and distribution of melanophores in three kinds of loaches might lead to the differences in these phenotypes. An important feature of melanophores was that they contained melanosomes where melanin particles are produced and stored(Hurbain et al., 2008). Melanosomes had phagocytic and secretory functions, and the development of melanosomes could be divided into four stages (Slominski, Tobin, Shibahara, \& Wortsman, 2004). The ultrastructure and the content of melanin granules were different in different stages (Schiaffino, 2010). Our data indicated that for BBL, melanosomes were mostly in stage four; for SBL, in stage three or stage four; for NBL, stage one to stage three. Therefore, there might be a close correlation between the phenotype and the maturity or quantity of melanosomes in the three kinds of loaches. 
The pigment content has a great influence on body color. Deng et al. (Deng, 2020) reported that the black skin of $P$. leopard was related to the contents of melanin and melaninase, while the red skin was related to the content of carotenoids. Our data indicated that the number of melanophores in BBL was the largest, while that in NBL was the smallest, which might be due to the different aggregation degrees of melanophores. The aggregation degree of melanophores in BBL was the highest, and the cell body was the biggest, therefore there were big blackspots in the dorsal skin of BBL. Our results showed that significant differences in melanin content and tyrosinase activity were observed between the dorsal skin and the abdominal skin in BBL, which was in line with the previous report that there was a positive correlation between melanin content and tyrosinase content(Giebel, Strunk, \& Spritz, 1991; Tief, Hahne, Schmidt, \& Beermann, 1996). Our results also indicated the body color and black spots of loaches were closely related to the composition and distribution of melanophores, and melanin content The visual color of xanthophores and erythrophores was reported to be mainly determined by the relative content and type of intracellular pigment particles (Bagnara., 1973). Our data indicated that there was no significant difference in lutein and total carotenoid contents among the three kinds of loaches. The reason for this result might be that fish themselves could not synthesize carotene and carotenoids, thus fish must obtain them by feeding (Ding, 2010). Zhu et al. (Zhu, 2003) reported that the muscle coloration of cultured fish could be increased by adding carotenoids to the feed. In this study, three kinds of loaches were reared in the same environment and fed with the diets with the same carotenoids, thus there was no significant difference in the intake amounts of carotenoids, further resulting in no significant difference in body color of three kinds of loaches.

\section{Conclusion}

Altogether, our results indicated that body color and blackspots of loaches are closely related to the melanophore distribution, melanin content, and tyrosinase content and activity.

\section{Declarations}

\section{Funding information}

This work was supported by Key scientific and technological projects in Jiangxi Province(2018ACF60014), National key Research and Development Grant (2018YFD0901700) and the earmarked fund for Jiangxi Agriculture Research System (JXARS-10).

\section{Conflict of interest}

The authors declare that they have no conflict of interest.

\section{Compliance with ethical standards}

Fish care and experimental protocols were performed in accordance with the guidelines for the Care and Use of Research Animals by the Institutional Animal Care and Use Committee of China.

The author agrees to participate and publish.

Our data and material are availability and transparency.

\section{Author contributions}

Conceptualization;Junqing Shneg, Methodology:Le Guan, Formal analysis and investigation:Bin Sheng,Writing - original draft preparation:Shiyu Geng ; Writing - review and editing: Di Wu, Funding acquisition: Yijiang Hong, Resources: Beijuan Hu, Supervision: Zhixiong Li.

\section{References}

Bagnara, J. (1998). Comparative anatomy and physiology of pigment cells in nonmammalian tissues. Pigmentary System. Retrieved from https://doi.org/10.1002/9780470987100.ch2

Bagnara., J., T. Hadley, M. E. (1973). Chromatophores and color change: the comparativa physiology of animal pigmentation. Quarterly Review of Biology. Retrieved from https://doi.org/10.1086/408042

Bian, F., Yang, X., Ou, Z., Luo, J., Tan, B., Yuan, M., Yang, R. (2019). Morphological Characteristics and Comparative Transcriptome Analysis of Three Different Phenotypes of Pristella maxillaris. Front Genet, 10,698. Retrieved from https://doi.org/10.3389/fgene.2019.00698

Cal, L., Suarez-Bregua, P., Cerdá-Reverter, J. M., Braasch, I., \& Rotllant, J. (2017). Fish pigmentation and the melanocortin system. Comparative Biochemistry and Physiology Part A: Molecular \& Integrative Physiology, 211, 26-33. Retrieved from https://doi.org/10.1016/j.cbpa.2017.06.001

Darias, M. J., Andree, K. B., Boglino, A., Fernandez, I., Estevez, A., \& Gisbert, E. (2013). Coordinated regulation of chromatophore differentiation and melanogenesis during the ontogeny of skin pigmentation of Solea senegalensis (Kaup, 1858). PLoS One, 8(5), e63005. Retrieved from https://doi.org/10.1371/journal.pone.0063005

Deng, C. C., S.L. Ye, H.Z. Qi, X.Z. Luo, J. (2020). Analysis of Pigment and Enzyme Levels of Plectropomus leopardus with Body Color Difference. Life Science Research 24(01), 15-20. Retrieved from https://kns.cnki.net/kcms/detail/detail.aspx?

dbcode=CJFD\&dbname=CJFDLAST2020\&filename=SMKY202001003\&v=ccspB4ZMSKpbUNBtiY6dydm1 mgjcwlmqf 183 THqzK\%25mmd2F0E55ybZ3z\%25mm

Page 5/13 
Ding, X. F. Y., Y.T., Jiang, R., Cai, C.F. Zhu,G.Y. Wang J.T. (2010). Effects of feed pigments on carotenoids $\rrbracket$ lutein content and tyrosinase activity in the skin and serum of Pelteobagrus fulvidraco. Journal of Fisheries of China, 34(11), 1728-1735. Retrieved from https://kns.cnki.net/kcms/detail/detail.aspx? dbcode=CJFD\&dbname=CJFD2010\&filename=SCKX201011014\&v=xznynB447TX\%25mmd2F8ihJZPUQLHCpM04\%25mmd2FHYV5p5s30W5yOlir07dZQT3Lk

Eom, D. S., Bain, E. J., Patterson, L. B., Grout, M. E., \& Parichy, D. M. (2015). Long-distance communication by specialized cellular projections during pigment pattern development and evolution. Elife, 4. Retrieved from https://doi.org/10.7554/eLife.12401.001

Frohnhofer, H. G., Krauss, J., Maischein, H. M., \& Nusslein-Volhard, C. (2013). Iridophores and their interactions with other chromatophores are required for stripe formation in zebrafish. Development, 140(14), 2997-3007. Retrieved from https://doi.org/10.1242/dev.096719

Fujii, R. (1993). Coloration and chromatophores. The Physiology of Fishes, 535-562. Retrieved from https://ci.nii.ac.jp/naid/10008672110/en/

Fujii, R. (2000). The regulation of motile activity in fish chromatophores. Pigment Cell Res, 13(5), 300-319. Retrieved from https://doi.org/10.1034/j.16000749.2000.130502.x

Giebel, L. B., Strunk, K. M., \& Spritz, R. A. (1991). Organization and nucleotide sequences of the human tyrosinase gene and a truncated tyrosinase-related segment. Genomics, 9(3), 435-445. Retrieved from https://www.ncbi.nlm.nih.gov/pubmed/1903356

Goda, M., \& Fujii, R. (1995). Blue Chromatophores in Two Species of Callionymid Fish. Zoological Science, 12(6), 811-813, 813. Retrieved from https://doi.org/10.2108/zsj.12.811

Greenwood, A. K., Cech, J. N., \& Peichel, C. L. (2012). Molecular and developmental contributions to divergent pigment patterns in marine and freshwater sticklebacks. Evol Dev, 14(4), 351-362. Retrieved from https://doi.org/10.1111/j.1525-142X.2012.00553.x

Guo, H., Huang, B., Qi, F., \& Zhang, S. (2007). Distribution and ultrastructure of pigment cells in the skins of normal and albino adult turbot, Scophthalmus maximus. Chinese Journal of Oceanology and Limnology, 25(2), 199-208. Retrieved from https://doi.org/10.1007/s00343-007-0199-1

Hirata, M. N., K. Kondo, S. (2005). Pigment cell distributions in different tissues of the zebrafish, with special reference to the striped pigment pattern. Dev Dyn, 234(2), 293-300. Retrieved from https://doi.org/10.1002/dvdy.20513

Hurbain, I., Geerts, W. J., Boudier, T., Marco, S., Verkleij, A. J., Marks, M. S., \& Raposo, G. (2008). Electron tomography of early melanosomes: implications for melanogenesis and the generation of fibrillar amyloid sheets. Proc Natl Acad Sci U S A, 105(50), 19726-19731. Retrieved from https://doi.org/10.1073/pnas.0803488105

Kelsh, R. N. (2004). Genetics and evolution of pigment patterns in fish. Pigment Cell Res, 17(4), 326-336. Retrieved from https://doi.org/10.1111/j.16000749.2004.00174.x

Kottler, V. A., Kunstner, A., \& Schartl, M. (2015). Pheomelanin in fish? Pigment Cell Melanoma Res, 28(3), 355-356. Retrieved from https://doi.org/10.1111/pcmr.12359

Maderspacher, F., \& Nusslein-Volhard, C. (2003). Formation of the adult pigment pattern in zebrafish requires leopard and obelix dependent cell interactions. Development, 130(15), 3447-3457. Retrieved from https://doi.org/10.1242/dev.00519

Nishimura, E. K., Suzuki, M., Igras, V., Du, J., Lonning, S., Miyachi, Y., Fisher, D. E. (2010). Key roles for transforming growth factor beta in melanocyte stem cell maintenance. Cell Stem Cell, 6(2), 130-140. Retrieved from https://doi.org/10.1016/j.stem.2009.12.010

Nishimura, E. K., Yoshida, H., Kunisada, T., \& Nishikawa, S. I. (1999). Regulation of E- and P-cadherin expression correlated with melanocyte migration and diversification. Dev Biol, 215(2), 155-166. Retrieved from https://doi.org/10.1006/dbio.1999.9478

Ou, Z. J. B. F. F. Y., R.B. Yang, X.F. (2018). Improved paraffin section method for observing iridophores in skin of Paramisgurnus dabryanus. Journal of Huazhong agricultural university, 37(04), 121-125. Retrieved from https://kns.cnki.net/kcms/detail/detail.aspx?

dbcode=CJFD\&dbname=CJFDLAST2018\&filename=HZNY201804017\&v=u3\%25mmd2BFpuL\%25mmd2BiG7J9ux6NVMaR7wccEA58Zj92jD02kMfMYBaQ\%2

Parichy, D., M. (2003). Pigment patterns: fish in stripes and spots. Curr Biol, 13(24), R947-950. Retrieved from https://doi.org/10.1016/j.cub.2003.11.038

Patterson, L. B., \& Parichy, D. M. (2013). Interactions with iridophores and the tissue environment required for patterning melanophores and xanthophores during zebrafish adult pigment stripe formation. PLoS Genet, 9(5), e1003561. Retrieved from https://doi.org/10.1371/journal.pgen.1003561

Schartl, M., Larue, L., Goda, M., Bosenberg, M. W., Hashimoto, H., \& Kelsh, R. N. (2016). What is a vertebrate pigment cell? Pigment Cell Melanoma Res, 29(1), 814. Retrieved from https://doi.org/10.1111/pcmr.12409

Schiaffino, M. V. (2010). Signaling pathways in melanosome biogenesis and pathology. Int J Biochem Cell Biol, 42(7), 1094-1104. Retrieved from https://doi.org/10.1016/j.biocel.2010.03.023

Singh, A. P., Schach, U., \& Nusslein-Volhard, C. (2014). Proliferation, dispersal and patterned aggregation of iridophores in the skin prefigure striped colouration of zebrafish. Nat Cell Biol, 16(6), 607-614. Retrieved from https://doi.org/10.1038/ncb2955 
Slominski, A., Tobin, D. J., Shibahara, S., \& Wortsman, J. (2004). Melanin pigmentation in mammalian skin and its hormonal regulation. Physiol Rev, 84(4), 1155-1228. Retrieved from https://doi.org/10.1152/physrev.00044.2003

Takahashi, G., \& Kondo, S. (2008). Melanophores in the stripes of adult zebrafish do not have the nature to gather, but disperse when they have the space to move. Pigment Cell Melanoma Res, 21(6), 677-686. Retrieved from https://doi.org/10.1111/j.1755-148X.2008.00504.x

Tief, K., Hahne, M., Schmidt, A., \& Beermann, F. (1996). Tyrosinase, the key enzyme in melanin synthesis, is expressed in murine brain. Eur J Biochem, 241(1), 12-16. Retrieved from https://doi.org/10.1111/j.1432-1033.1996.0012t.x

Van der Salm, A. L., Martinez, M., Flik, G., \& Bonga, S. E. W. (2004). Effects of husbandry conditions on the skin colour and stress response of red porgy, Pagrus pagrus. Aquaculture, 241(1-4), 371-386. Retrieved from https://doi.org/10.1016/j.aquaculture.2004.08.038

Yanar, M., \& Nazmi, T. (1999). The Effect of Zeaxanthin and Tank Color on Pigmentation and Growth of Goldish ( Carassius auratus). Turkish Journal of Biology(3), 303-308. Retrieved from https://journals.tubitak.gov.tr/biology/abstract.htm?id=3272

Yao, X. H. W., S. Bao,B.L. (2020). Comparative analysis on the countershading between several marine pelagic fishes and demersal fishes. Journal of Shanghai Ocean University, 29(02), 199-208. Retrieved from https://kns.cnki.net/kcms/detail/detail.aspx?

dbcode=CJFD\&dbname=CJFDLAST2020\&filename=SSDB202002005\&v=sl\%25mmd2Bc0hJph1NkSSKpLFJsYjVofTbeiPLXeG\%25mmd2F\%25mmd2F1wt9XI

Yu, L. W. C., S.Y. Wang, J. Wang, C.H. (2020). Formation of melanin and mitfa in-situ in the Oujiang color common carp(Cyprinus carpio var.color). Journal of Shanghai Ocean University, 29(04), 481-488. Retrieved from https://kns.cnki.net/kcms/detail/detail.aspx?

dbcode=CJFD\&dbname=CJFDLAST2020\&filename=SSDB202004001\&v=sl\%25mmd2Bc0hJph109CpAioNe04Dm1nmYI6apqHYTXIZuQtPUN3CrSeAlwEV\%25

Zarnescu, O. (2007). Ultrastructure of the skin melanophores and iridophores in paddlefish, Polyodon spathula. Micron, 38(1), 81-84. Retrieved from https://www.ncbi.nlm.nih.gov/pubmed/16713272

Zhang, W. (2006). Studies on Cytogenetic and Reprductive Biology of Loach(Misgurnus anguillicaudatus)from Poyang Lake. NanChang University Retrieved from https://kns.cnki.net/kcms/detail/detail.aspx?

dbcode=CMFD\&dbname=CMFD0506\&filename=2006122032.nh\&v=NMLBDa5klfx\%25mmd2BBf2H\%25mmd2B8e\%25mmd2FCfRwNbhUMwHiXz9\%25mmd2l Available from Cnki

Zhang, Y. P., Wang, Z. D., Guo, Y. S., Liu, L., Yu, J., Zhang, S., Liu, C. W. (2015). Morphological Characters and Transcriptome Profiles Associated with Black Skin and Red Skin in Crimson Snapper (Lutjanus erythropterus). Int J Mol Sci, 16(11), 26991-27004. Retrieved from https://doi.org/10.3390/ijms161126005

Zhu, Y. F. M. K. S. (2003). A review of carotenoid of pigmentation additives in fish feeds. Acta Hydrobiologica Sinica(02), 196-200. Retrieved from https://kns.cnki.net/kcms/detail/detail.aspx?

dbcode=CJFD\&dbname=CJFD2003\&filename=SSWX200302017\&v=1c0pu6GSUqwAgpp\%25mmd2FqvS1ho3963p332koLX9g1kScCTENKME8F07sa9L24vRz

\section{Figures}
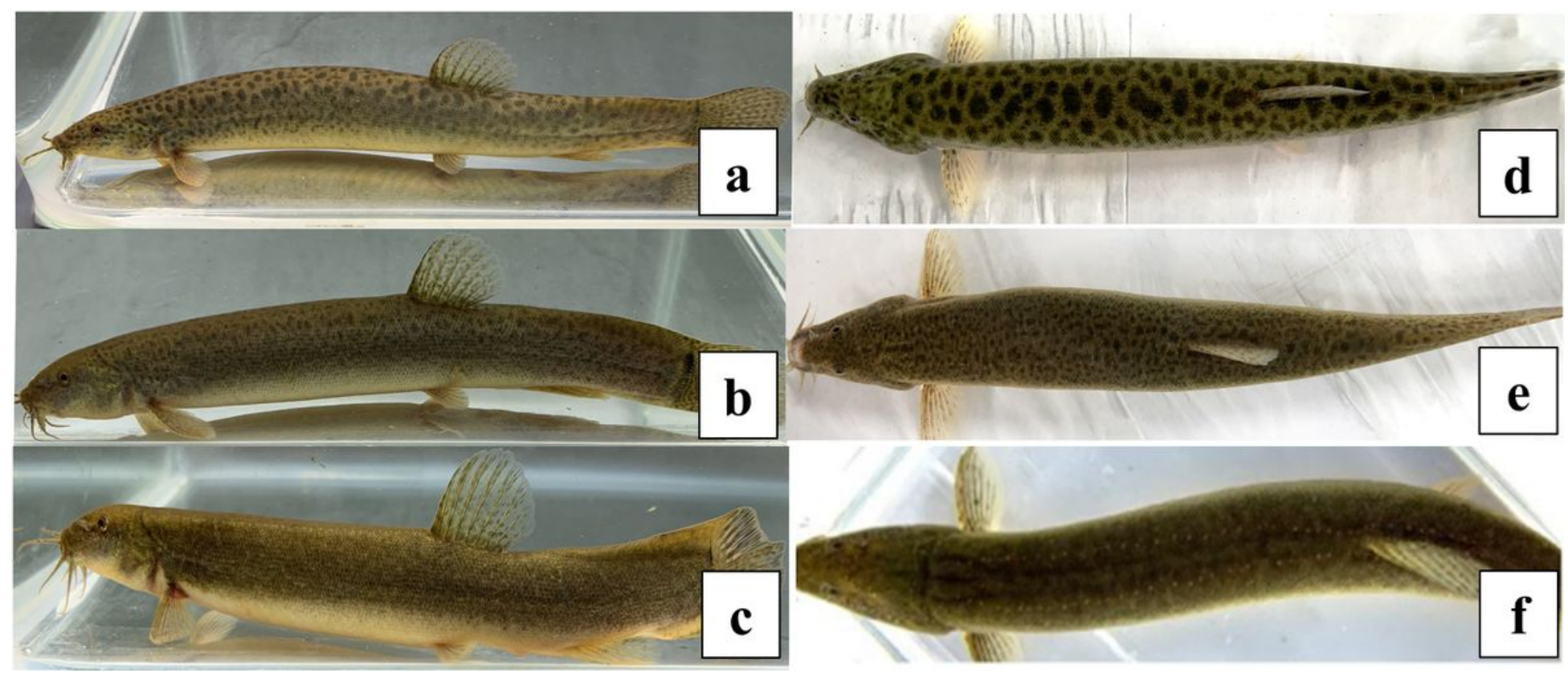

\section{Figure 1}

External morphology of BBL, SBL and NBL. 


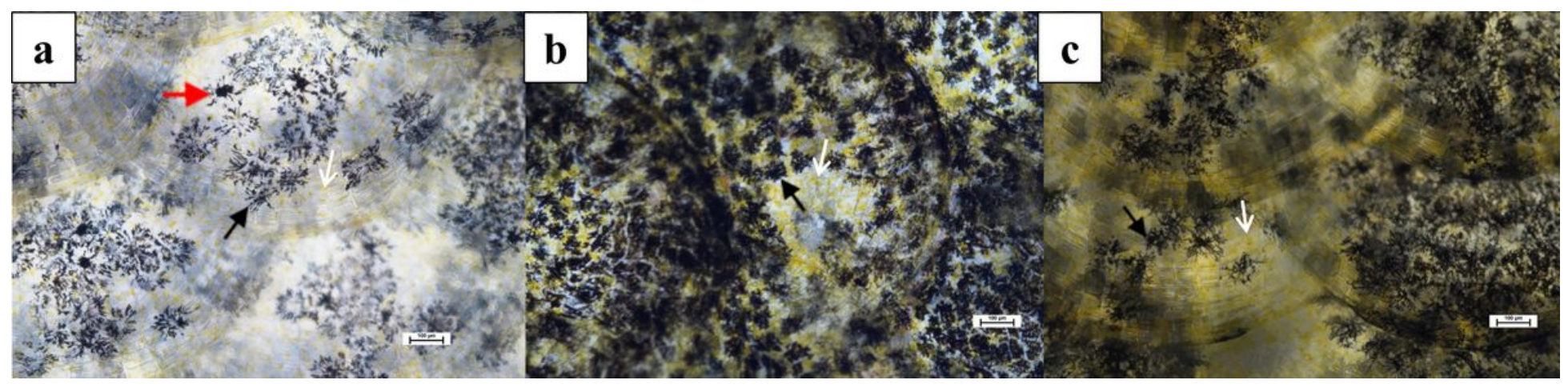

Figure 2

Distribution of pigment cells in the dorsal epidermis of three kinds of loaches

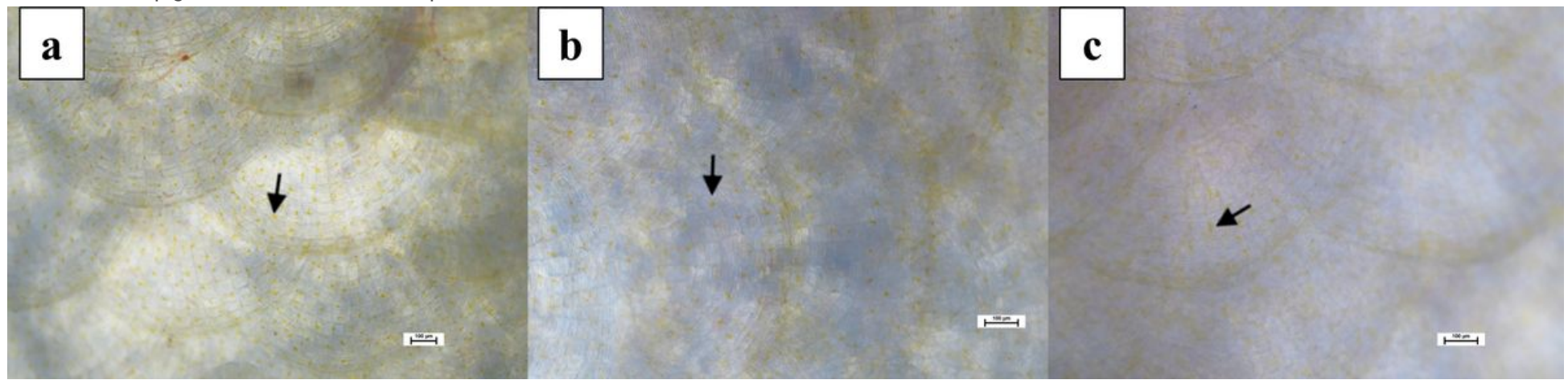

\section{Figure 3}

Distribution of skin pigment cells in abdomen of three kinds of loaches

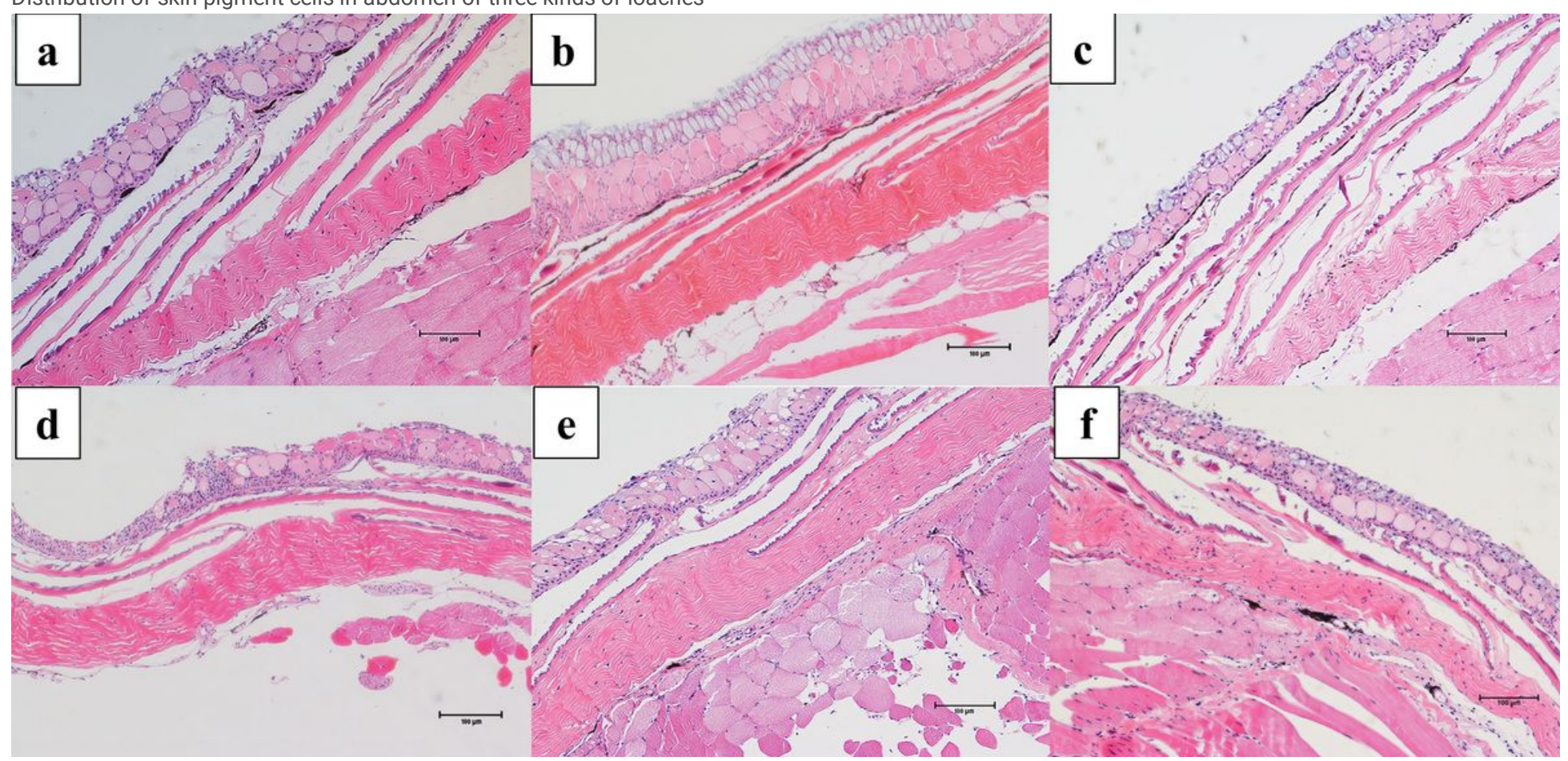

\section{Figure 4}

Skin microstructure of three kinds of loaches 


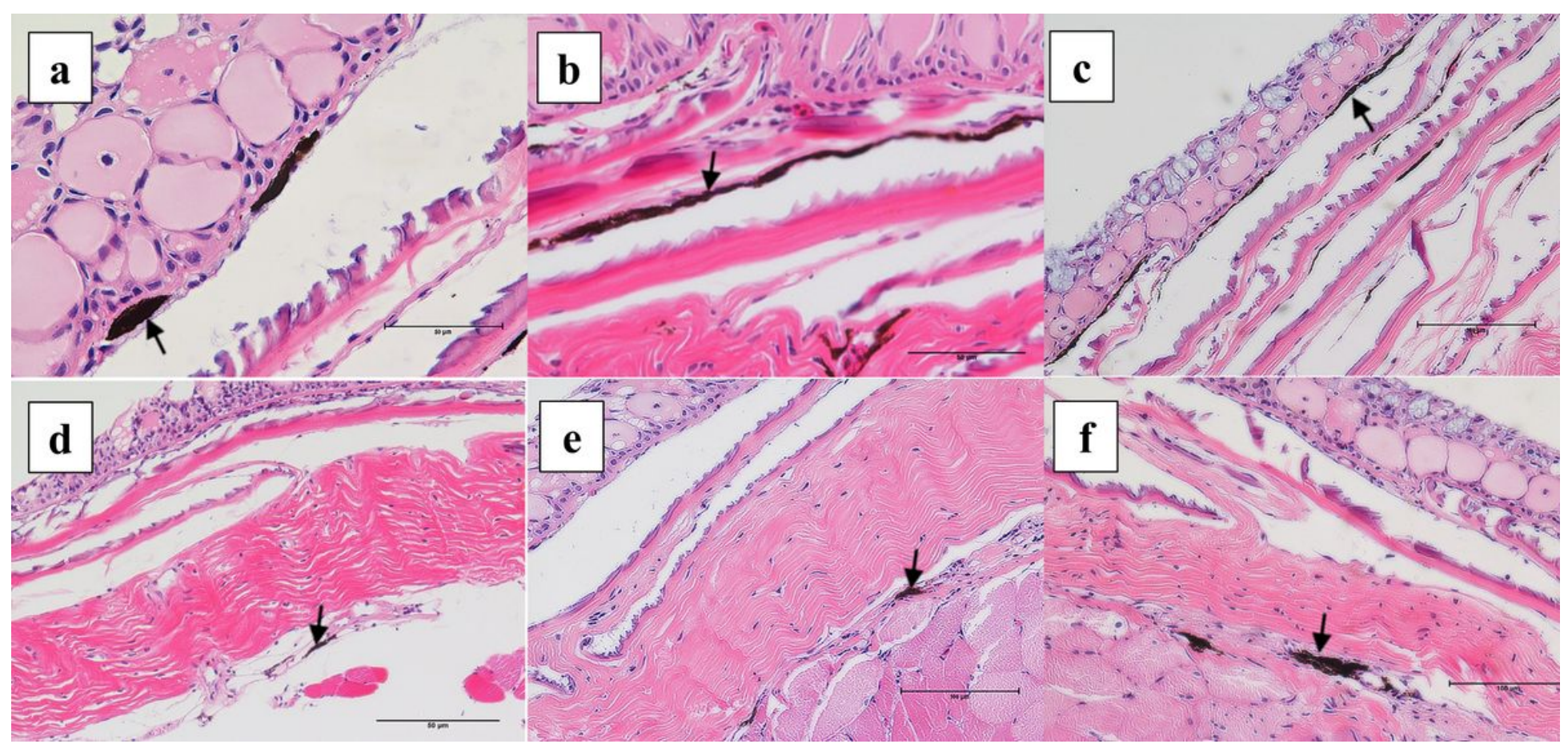

\section{Figure 5}

Distribution of melanocytes in skin of three kinds of loaches

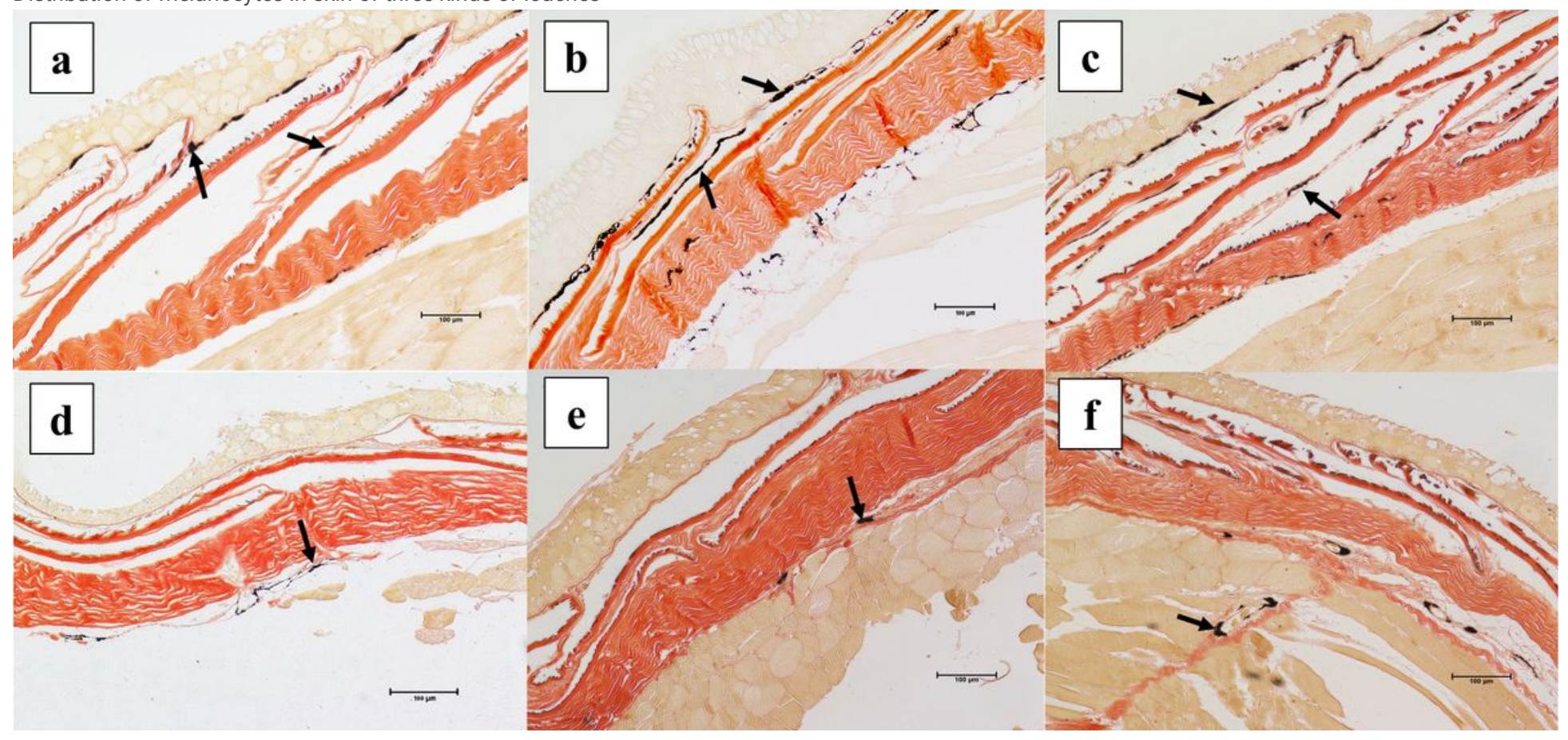

Figure 6

Distribution of melanocytes in skin of three kinds of loaches with MF staining 


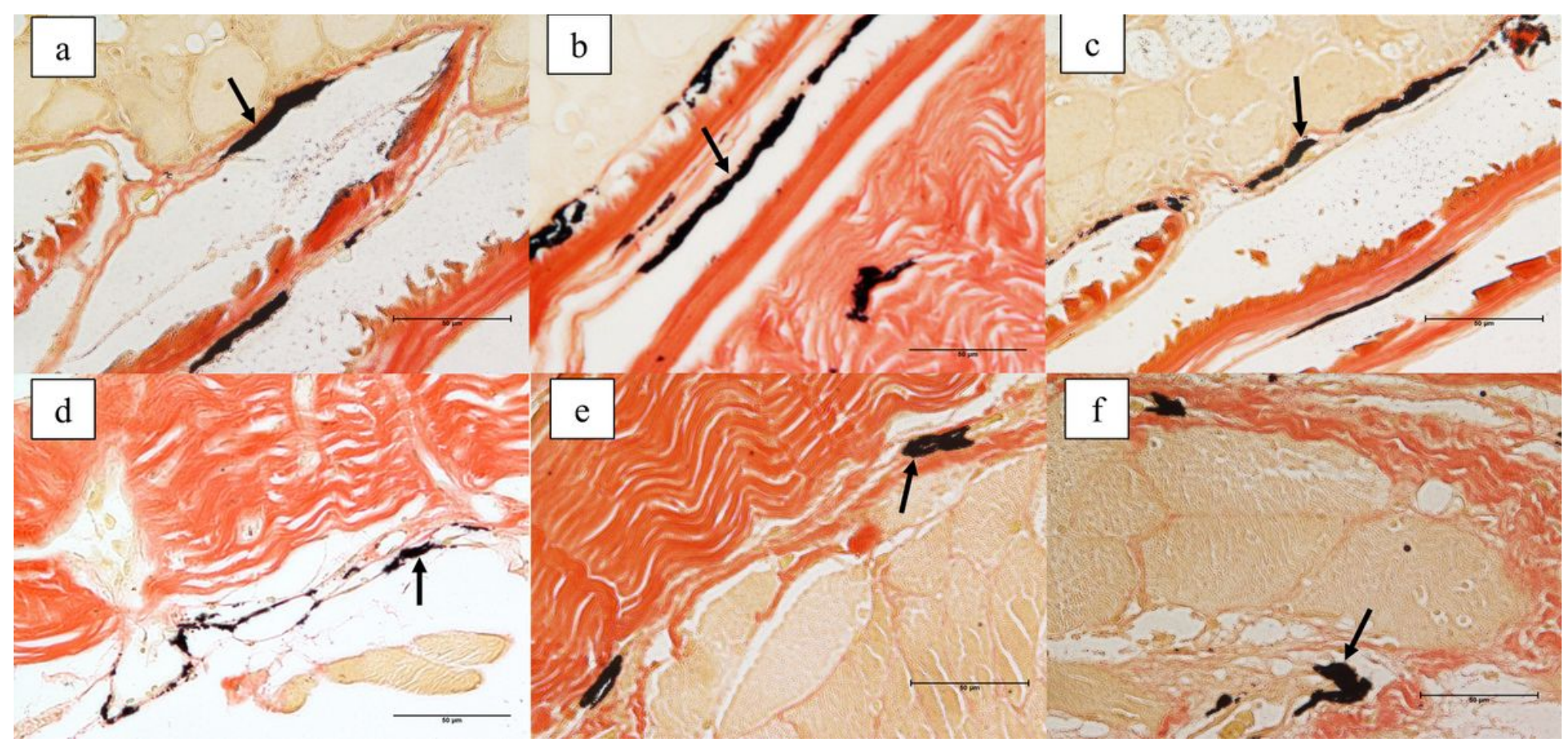

Figure 7

Melanocytes morphology in skin of three kinds of loaches

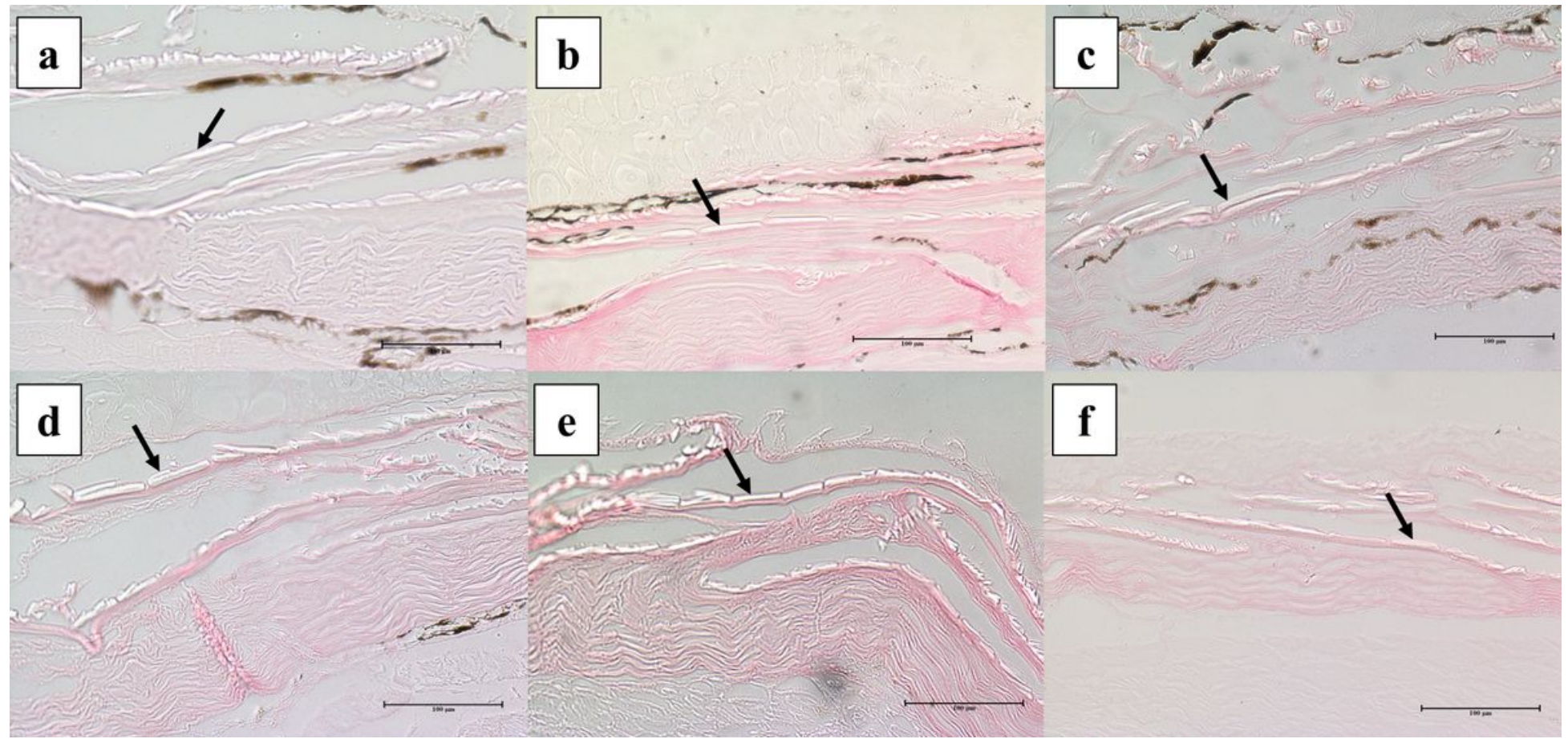

Figure 8

Iridophores morphology in skin of three kinds of loaches 


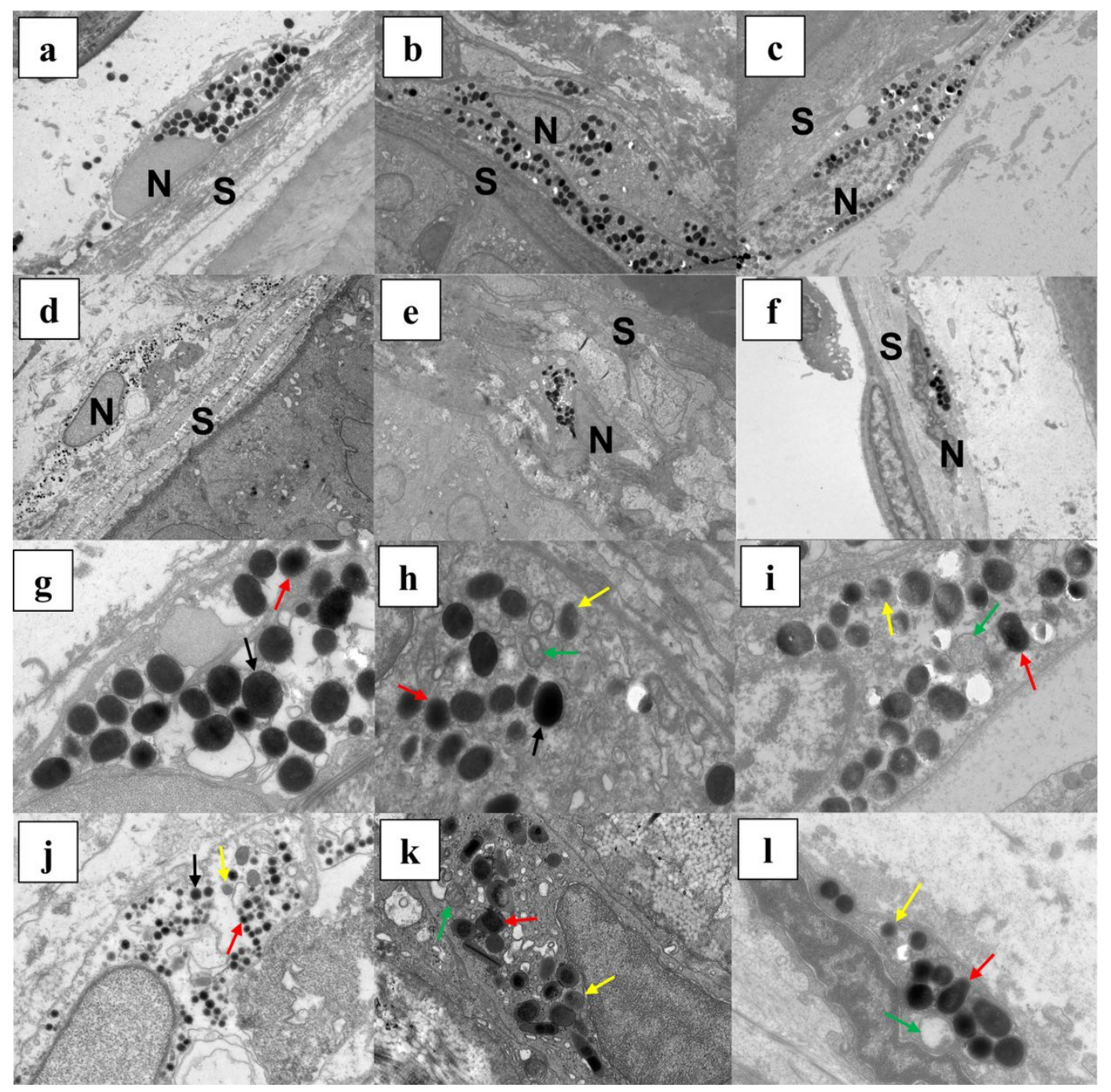

Figure 9

Ultra thin sections of skin of three kinds of loaches
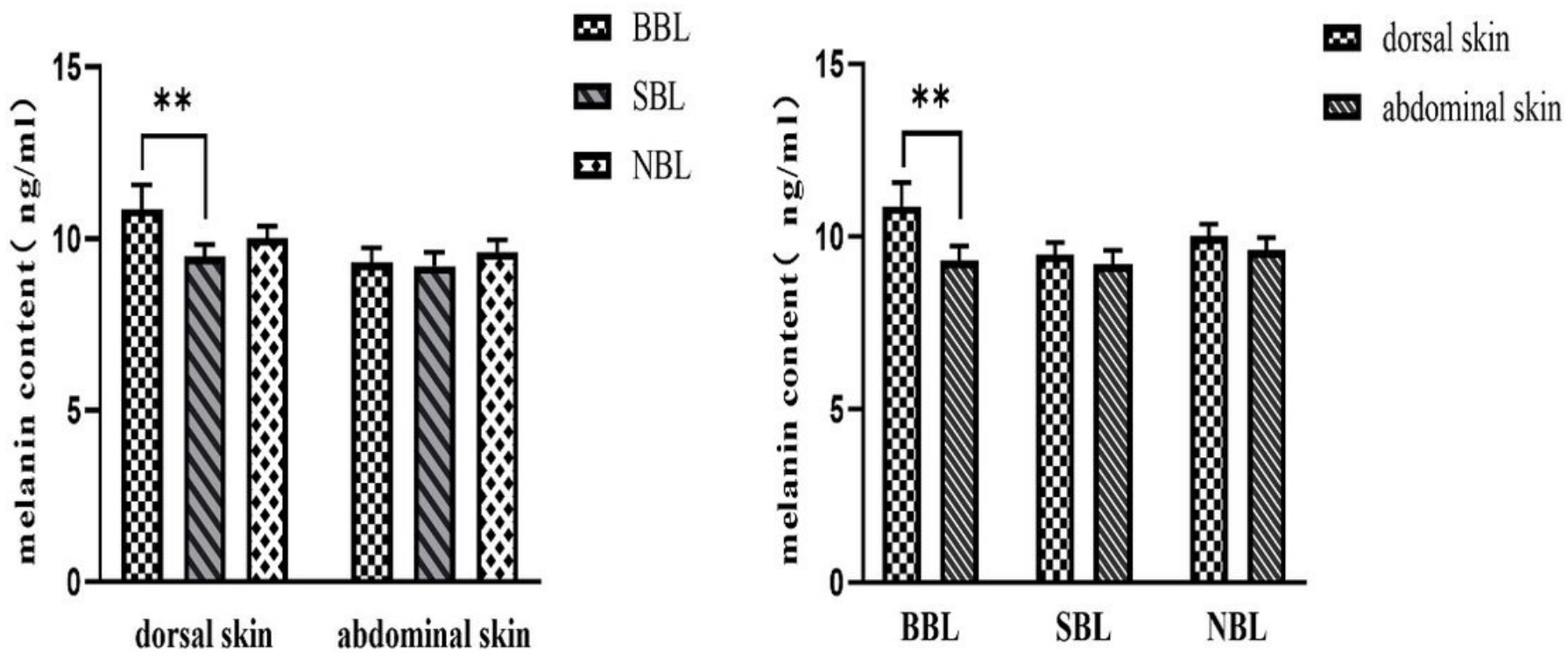

Figure 10 

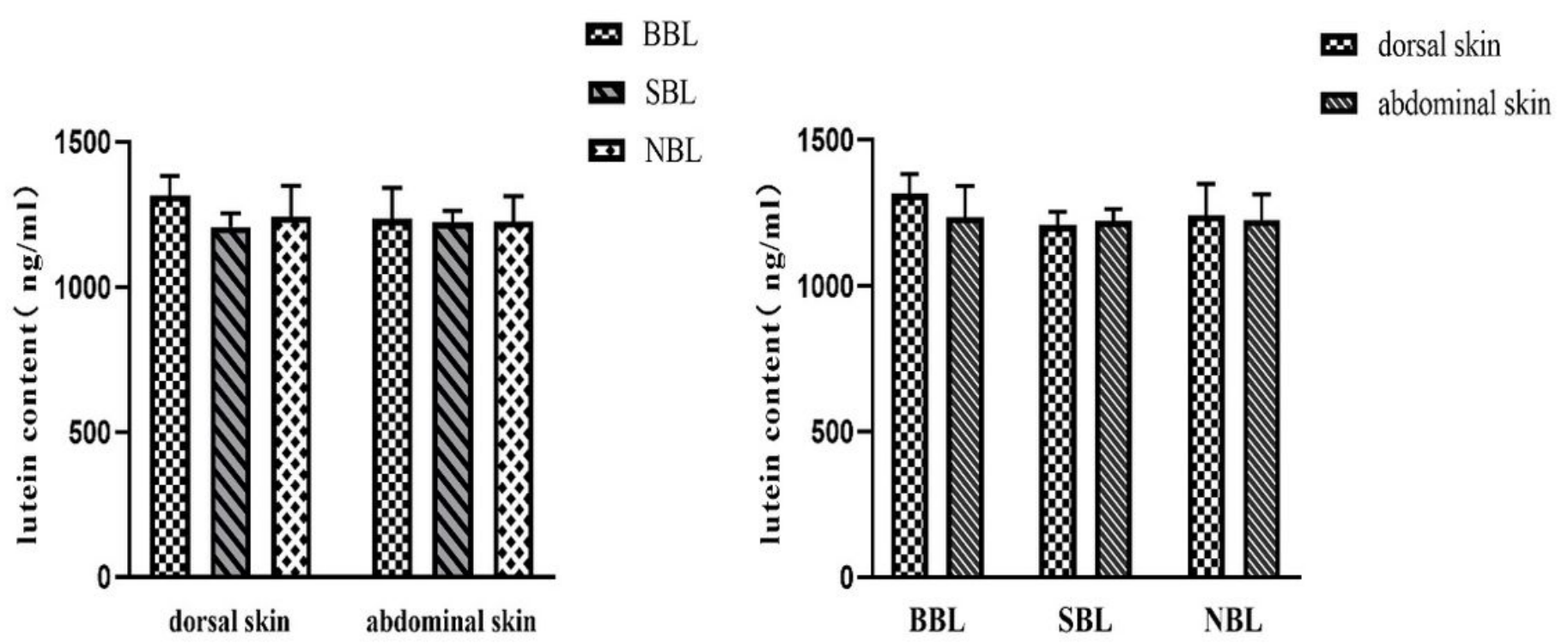

Figure 11

Lutein content of three kinds of loaches
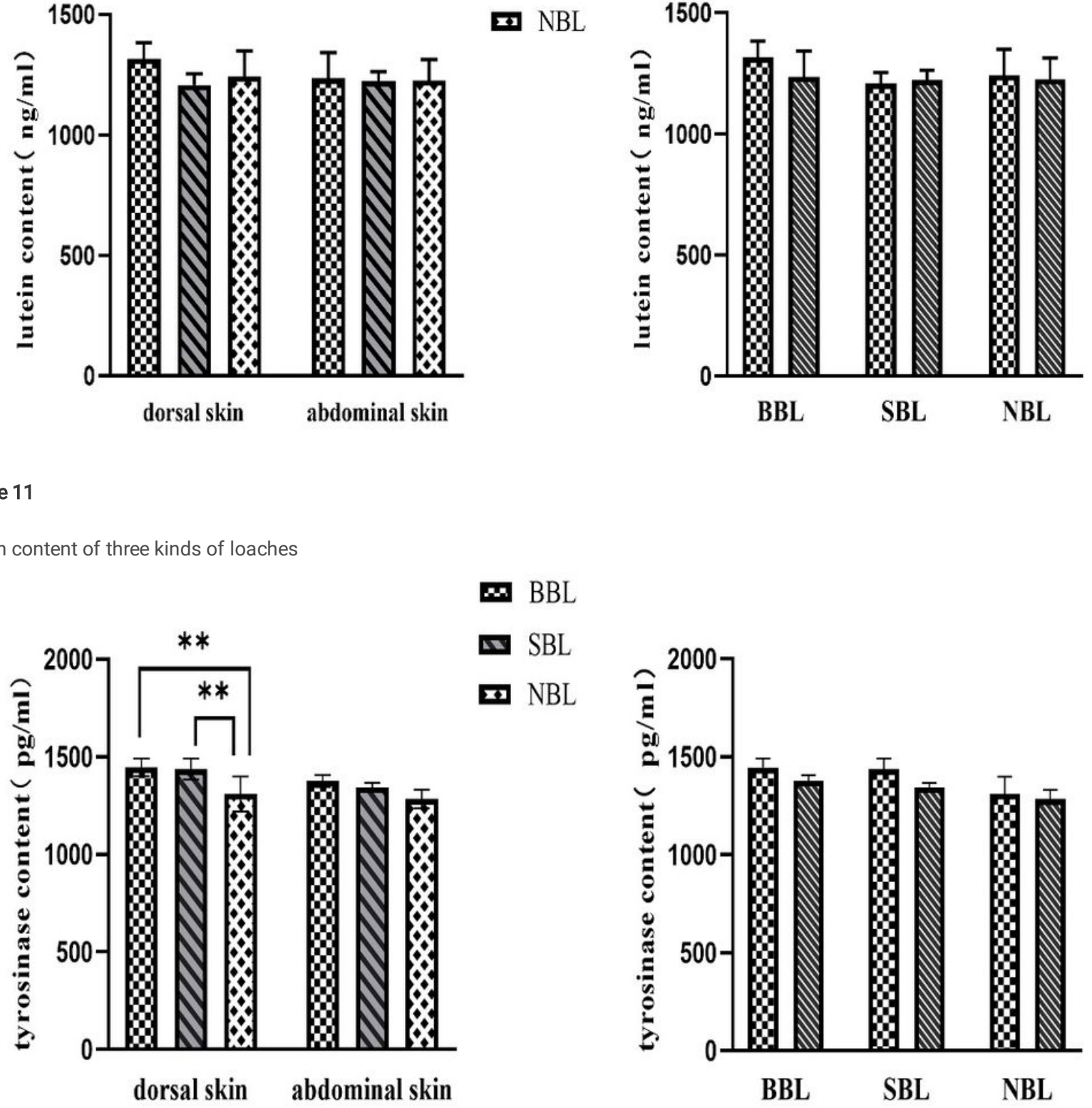

aBL

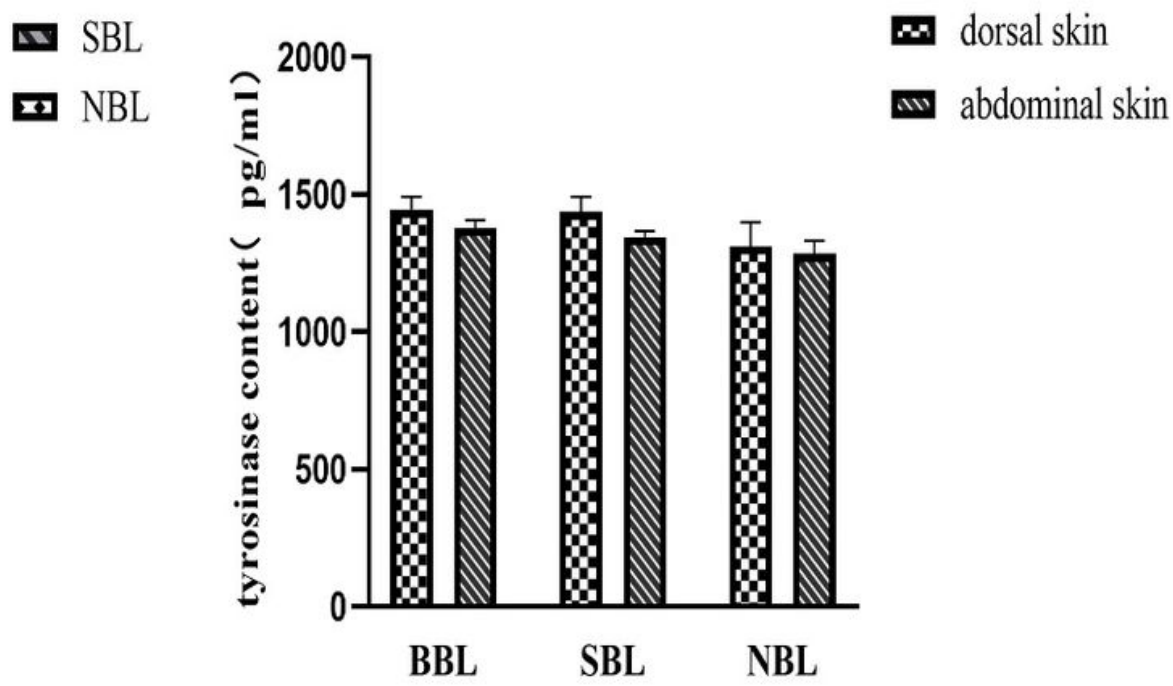

Figure 12

Content of total carotenoids in three kinds of loaches 


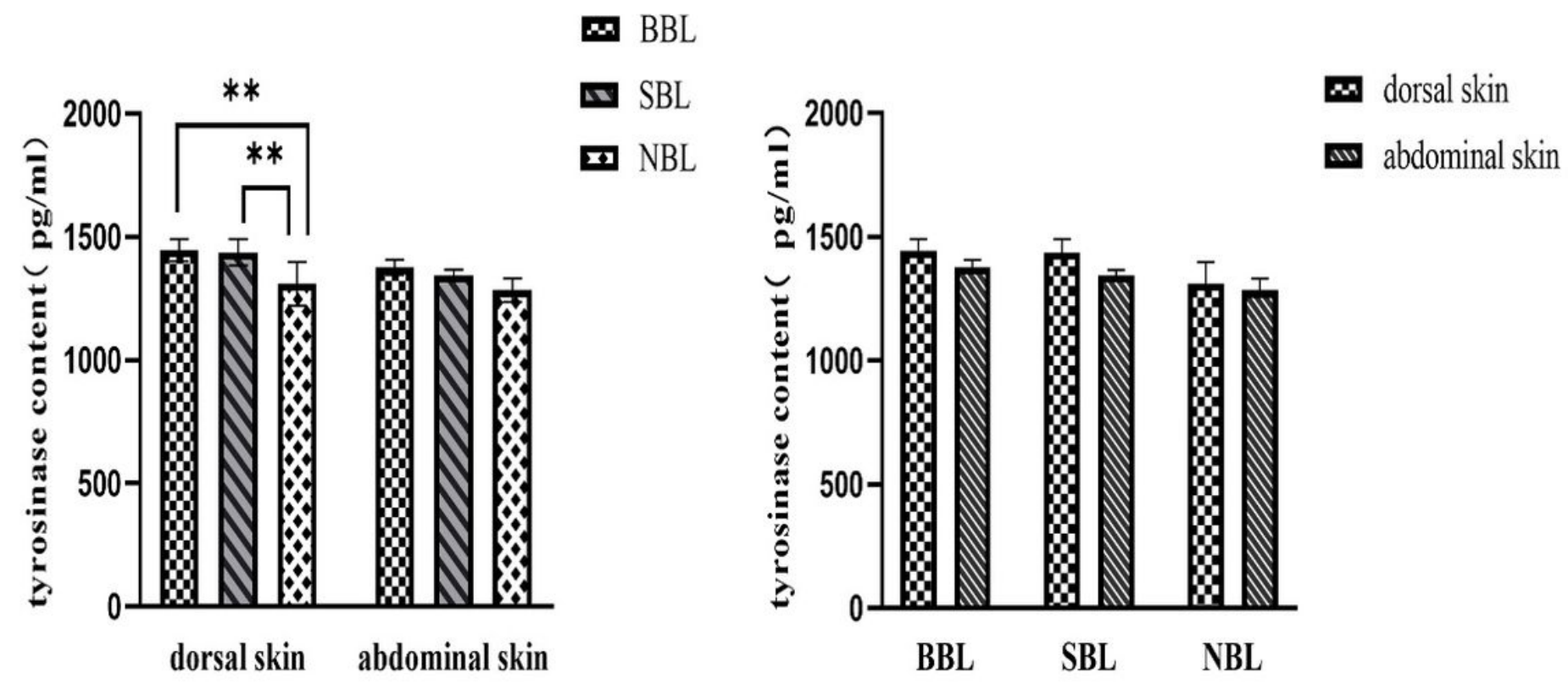

Figure 13

Tyrosinase content of three kinds of loaches.

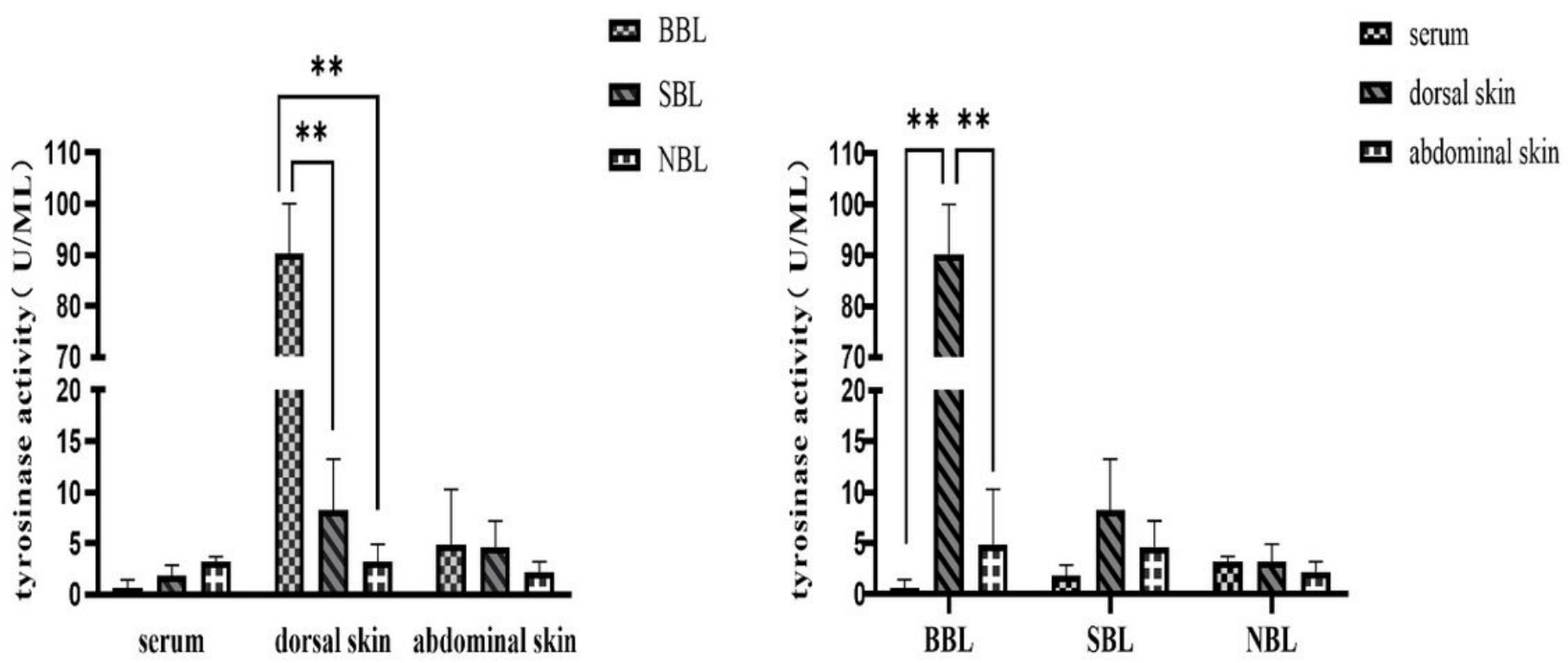

Figure 14

Tyrosinase activity in three kinds of loaches. 